\title{
Visibility of research in universities: The triad product-researcher- institution. Case: Latin american countries
}

Vásquez, Carmen; Torres Samuel, Maritza; Viloria Silva, Amelec Jesus; Borrero Crissien, Tito Jose; Varela Izquierdo, Noel; Lis Gutierrez, Jenny Paola; Gaitan, Mercede.

\begin{abstract}
Considering variables associated with the research product, the researcher, the university, and the country, the scientific visibility of the university research function, requires coordinating actions achieving favorable results. This paper describes a Product-Researcher-Institution (PRI) visibility scheme, in addition to presenting results with database of large size (official website, Open Access journals, ResearchGate, Google Scholar, Academia and Curriculum Vitae Latinoamericano, Webometrics Ranking) collected from universities in Argentina, Brazil, Chile, Colombia and Mexico, regarding the components of this proposal.
\end{abstract}

\section{Keywords}

Database Latin America, Research function, Researcher, Scientific visibility, Universities, Webometrics ranking 